\title{
Ressuscitação Cardiopulmonar em Pacientes com COVID-19
}

\author{
Cardiopulmonary Resuscitation in COVID-19 Patients
}

\author{
Gilson Soares Feitosa-Filho ${ }^{1,2}$, Rogger Gonçalves Ribeiro ${ }^{1}$, \\ Júlia Micheli Perez ${ }^{2}$, Ênio Santana ${ }^{1}$ \\ ${ }^{1}$ Hospital Santa Izabel - Santa Casa da Bahia; ${ }^{2}$ Escola Bahiana de \\ Medicina e Saúde Pública; Salvador, Bahia, Brasil
}

Correspondence addresses: Dr. Gilson Soares Feitosa Filho gilsonfeitosafilho@yahoo.com.br

Received: April 9, 2020

Revised: May 14, 2020

Accepted: May 15, 2020

Published: May 31, 2020

Data Availability Statement: All relevant data are within the paper and its Supporting Information files.

Funding: This work was the result of authors' initiative. There was no support of research or publication funds.

Competing interests: The authors have declared that no competing interests exist.

\section{Copyright}

(C) 2020 by Santa Casa de Misericórdia da Bahia.

All rights reserved.

ISSN: 2526-5563
As manobras de ressuscitação cardiopulmonar (RCP) durante a pandemia de COVID-19 em pacientes internados graves é requerida mais habitualmente. De uma maneira geral, 0 paciente sofre a parada cardiorrespiratória em decorrência da hipóxia que a Síndrome Respiratóra Aguda Grave (do inglês severe acute respiratory sundrome - SARS) leva. Entretanto, pacientes com arritmias ventriculares e choque já estão predispostos à parada cardiorrespiratória. Entretanto, é importante a equipe médica saber quando ressuscitar ou não o paciente, principalmente em decorrência da possível falta de Equipamentos de Proteção Individual (EPIs) da equipe, o que pode levar a um risco alto de contaminação dos envolvidos. Desta forma, as etapas, equipes e protocolos devem ser seguidos à risca na salvaguarda do pacente e da equipe médica.
Palavras-chave:
Ressuscitação
Cardiopulmonar
(RCP);
Parada Cardiorrespiratória; EPIs.

Cardiopulmonary resuscitation (CPR) maneuvers during the COVID-19 pandemic in critically ill inpatients are more commonly required. In general, the patient undergoes cardiorespiratory arrest due to the hypoxia that the Severe Acute Respiratory Syndrome (SARS) takes. However, patients with ventricular arrhythmias and shock are already predisposed to cardiorespiratory arrest. However, it is important for the medical team to know when to resuscitate the patient or not, mainly due to the possible lack of Personal Protective Equipment (PPE) on the team, which can lead to a high risk of contamination of those involved. Thus, the steps, teams and protocols must be strictly followed to safeguard the patient and the medical team.

Keywords: Cardiopulmonary Resuscitation (CPR); Cardiorespiratory Arrest; PPE.

\section{Introdução}

As manobras de ressuscitação cardiopulmonar (RCP) são as mais urgentes de todas as emergências. Em um cenário de doença altamente contagiosa como a COVID-19, precauções especiais são necessárias. Aerossóis são produzidos durante as manobras de compressão torácica e, principalmente, durante as ventilações, o que pode trazer risco potencial de contaminação à equipe assistente. ${ }^{1}$

A insuficiência respiratória secundária à síndrome do desconforto respiratório agudo, a injúria miocárdica, as arritmias ventriculares e choque 
são acometimentos comuns nos pacientes críticos e predispõem à parada cardiorrespiratória (PCR) em pacientes com COVID-19, ${ }^{2}$ além de fenômenos tromboembólicos. As arritmias ventriculares são desencadeadas comumente por mecanismos de lesão miocárdica, como isquemia e miocardite, mas também podem raramente ocorrer na vigência de medicações que alargam o intervalo QT (como Azitromicina e Hidroxicloroquina), as quais constam em alguns protocolos de tratamento para o novo coronavírus.

A RCP traz riscos adicionais aos profissionais de saúde por várias razões. Primeiro, sua execução pode envolver inúmeros procedimentos geradores de aerossóis, incluindo compressões torácicas, ventilação por pressão positiva e estabelecimento de via aérea avançada. Durante estes procedimentos, as partículas virais podem permanecer suspensas no ar com meia-vida de aproximadamente 1 hora e, desta forma, serem inaladas pelas pessoas que estejam próximas. $^{3}$ Segundo, os esforços da RCP requerem várias pessoas, as quais estão perto umas das outras e do paciente. 4 Além disso, estes são os eventos nos quais as necessidades imediatas de RCP no paciente com COVID-19 podem gerar falhas nas práticas de controle de infecção.

A PCR que acontece em pacientes com esta doença, geralmentepor hipóxia, tem mais chance de ser revertida quando tratada precocemente. Casos de pacientes em apneia por muito tempo geralmente têm prognóstico desfavorável, e analisando aspectos éticos e morais do médico responsável em reanimar um paciente sem os equipamentos de proteção individuais completos, deve ser sempre considerada a não realização ou término precoce dos esforços.

$\mathrm{O}$ atendimento a vítimas em PCR é uma emergência máxima. Exige passos bem treinados e coordenados em função do estresse que lhe é peculiar. Em um cenário de COVID-19, todos os passos devem ser refletidos antes, visto que o risco de contaminação dos próprios socorristas é real e potencialmente muito grave.
Várias ações na RCP são realizadas com fracos níveis de evidências, uma vez que essa emergência máxima dificulta a realização de estudos com a qualidade que habitualmente vemos em outras áreas da Cardiologia. As recomendações próprias à RCP nesse cenário são ainda menos embasadas em evidências adequadas.

Vários serviços do mundo fizeram adaptações próprias, e o ILCOR e outras entidades tentam continuamente atualizar as recomendações baseadas principalmente em opiniões de experts

\section{Etapas do Atendimento Intra-Hospitalar}

Antes de tudo, é preciso ficar bem claro o princípio número 1 do atendimento de RCP: a segurança do socorrista é fundamental. Ainda que a PCR seja uma urgência máxima, todos os profissionais de saúde devem usar equipamentos de proteção individual (EPIs) antes de entrar em cena de PCR suspeito de COVID-19. Neste ínterim, é igualmente necessário reduzir o número de pessoas na zona de atuação de RCP e todos nela presentes devem estar cientes da suspeita de COVID-19. Espera-se que 2 a 4 profissionais estejam envolvidos diretamente com o atendimento.

Assim que algum socorrista identificar a ausência de consciência de um paciente, a equipe de atendimento deve ser acionada e o pulso checado durante 5 a 10 segundos.

Se o ritmo ao monitor for FV/TV sem pulso, a prioridade máxima deve ser dada ao choque precoce. Se houver um segundo socorrista imediatamente paramentado, pode-se iniciar as compressões torácicas de qualidade (Tabela 1) sem ventilação, enquanto o desfibrilador é preparado. Idealmente, um plástico ou lençol deve ser colocado sobre as vias aéreas do paciente, impedindo que aerossóis se distribuam pelo ambiente.

O choque pode ser aplicado com desfibrilador convencional (aplicando pressão aproximada de $13 \mathrm{~kg}$ ) ou com as pás de marcapasso transcutâneo 
Tabela 1. Compressões torácicas de qualidade.

Velocidade de compressões entre 100-120 vezes por minuto

Aprofundar o tórax em $5 \mathrm{a} 6 \mathrm{~cm}$

Permitir a descompressão completa do tórax

Velocidade de compressão $=$ velocidade de descompressão

Se disponível, checar se capnógrafo mostra $\mathrm{PetCO}_{2}>10 \mathrm{mmHg}$

Se disponível, checar se PA invasiva diastólica $>20 \mathrm{mmHg}$

(permitindo manter equipe mais afastada do paciente e agilizando a dinâmica do próximo choque).

Em uma revisão sistemática, ${ }^{5}$ não foi encontrada evidência de que a desfibrilação gera aerossol. Se ela ocorrer, seria de curta duração. Além do mais, o uso de pás adesivas significa que a desfibrilação pode ser realizada sem contato direto entre o operador do procedimento e o paciente. De acordo com tal racional, sugere-se que os profissionais de saúde possam considerar a desfibrilação antes mesmo de colocar os EPIs em situações nas quais o profissional avalia que o benefício da execução do procedimento supera o risco (posicionamento de boa prática). ${ }^{6}$

A intubação deve ser realizada pelo médico mais experiente presente. Devese parar as compressões e, se disponível, usar vídeolaringoscópio, objetivando maior rapidez e tentativa única com segurança. Se uma segunda tentativa for necessária, considerar uso de dispositivos supraglóticos (máscara laríngea) ou cricotireoidostomia como forma de via aérea definitiva. Ainda que em alguns protocolos possa ser usada ventilação não-invasiva com filtro e boa vedação, não recomendamos pelo alto risco de contaminar o ambiente com aerossóis. Não há checagem de posição do tubo com ventilações por AMBU. Deve-se imediatamente instalar a ventilação mecânica em circuito fechado com os parâmetros descritos na Tabela 2. Deve- se sempre usar filtros HME e HEPA para dificultar a propagação do vírus no circuito e no ambiente.

Tabela 2. Como deve ser a ventilação mecânica durante a RCP em COVID-19.

\begin{tabular}{l}
\hline Circuito fechado, modo assíncrono (em PCV) \\
\hline Desligar função trigger (evitar auto-trigger) \\
\hline Frequência respiratória de 10 a $12 \mathrm{ipm}$ \\
\hline $\mathrm{FiO}_{2}$ de $100 \%$ \\
\hline Tempo inspiratório de 1 segundo \\
\hline $\begin{array}{l}\text { PEEP de zero (pode-se deixar PEEP de } 5 \text { para } \\
\text { ritmos não chocáveis) }\end{array}$ \\
\hline Desligar os alarmes \\
\hline
\end{tabular}

As compressões seguem continuamente e, passados 2 minutos, nova desfibrilação deve ser tentada caso o paciente mantenha FV/TVSP. Os momentos de administração de adrenalina e amiodarona seguem os protocolos convencionais.

O paciente em posição prona (decúbito ventral), quando conectado ao ventilador mecânico, pode ser reanimado na mesma posição, utilizando o desfibrilador em posição anteroposterior e as compressões torácicas em nível de vértebras torácicas T7-T10. Deve-se monitorar a qualidade das compressões com capnógrafo, sendo indicado reverter a posição se as compressões estiverem inadequadas. Caso o paciente esteja em posição prona mas não esteja conectado à ventilação mecânica, deverá ser colocado na posição supina antes da RCP.

\section{Quando Não Ressuscitar?}

É importantíssimo rediscutir quando não iniciar a RCP ou mesmo parar a RCP. Não existem recomendações objetivas, mas cada vez mais é necessário criar uma cultura de discutir antecipadamente com o próprio paciente e família até onde devem ir os esforços caso ocorra uma má evolução. Isso 
é mais comum em outros países, mas ainda muito incipiente no Brasil.

A RCP em pacientes com baixíssima chance de boa recuperação pode fazer mal ao paciente, à família e ao sistema, especialmente no cenário de COVID-19 com escassez de leitos aos que precisam. As decisões de não realizar RCP devem estar adequadamente documentadas e comunicadas à equipe. Os cuidados paliativos e de terminalidade devem seguir a política local e institucional (Figura 1). A discussão antecipada evita esforços para uma RCP fútil, expondo toda uma equipe previamente saudável.

As manobras de RCP devem ser administradas de forma inteligente, de modo a salvar mais vidas, sem colocar a equipe em risco.

Figura 1. Algoritmo de RCP em paciente COVID-19.

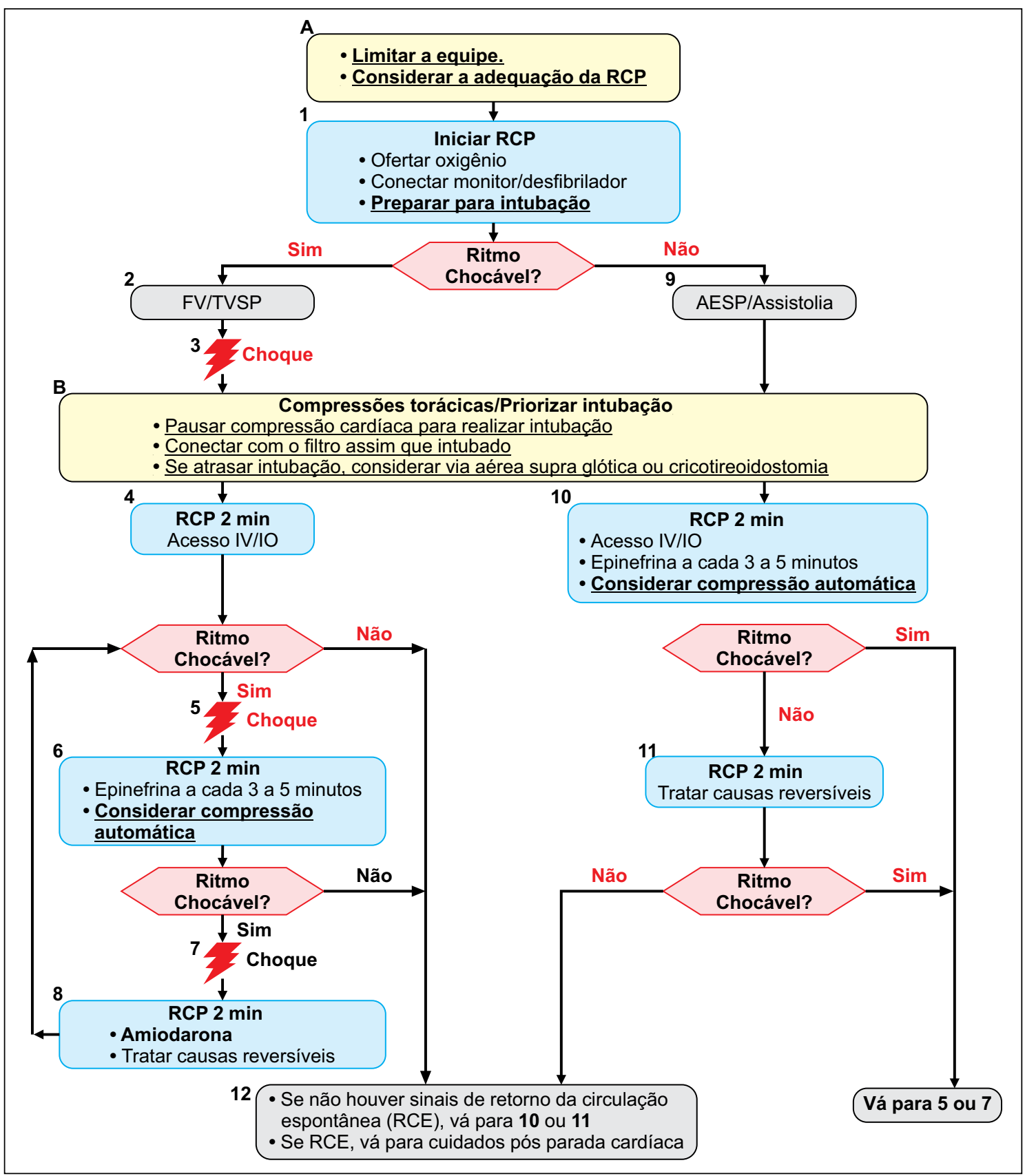




\section{Referências}

1. Guimarães HP, Timerman $\mathrm{S}$, Correa $\mathrm{T}$, et al. Recomendações para Ressuscitação Cardiopulmonar de pacientes com diagnóstico ou suspeita de COVID-19. Assoc Bras Med Emergência (ABRAMEDE), Assoc Med Intensiva Bras (AMIB), Soc Bras Cardiol [Internet] 2020;Available from: https://www.portal.cardiol.br/post/recomendaçõespara-ressuscitação-cardiopulmonar-de-pacientescom-diagnóstico-ou-suspeita-de-covid-19.

2. Huang C, Wang Y, Li X, et al. Clinical features of patients infected with 2019 novel coronavirus in Wuhan, China. Lancet 2020;395:497-506.

3. Edelson DP, Sasson C, Chan PS, et al. Interim Guidance for Basic and Advanced Life Support in Adults, Children, and Neonates With Suspected or Confirmed COVID-19:From the Emergency
Cardiovascular Care Committee and Get With the Guidelines ${ }^{\circledR}$-Resuscitation Adult and Pediatric Task Forces of th. Circulation. 2020;141:e933-e943.

4. Doremalen N van, Bushmaker T, Morris DH, et al. Aerosol and Surface Stability of SARS-CoV-2 as Compared with SARS-CoV-1. New Eng J Med 2020;386(16):1564-7.

5. Couper K, Taylor-Phillips S, Grove A, et al. COVID-19 infection risk to rescuers from patients in cardiac arrest. Consensus on science with treatment recommendations: International Liaison Committee on Resuscitation (ILCOR). 2020. https://costr.ilcor. org/document/covid-19-infection-risk-to-rescuersfrom-patients-in-cardiac-arrest.

6. International Liaison Committee on Resuscitation [homepage na internet]. COVID-19 Practical Guidance for Implementation [acesso em 27 jun 2020]. Disponível em: https://www.ilcor.org/covid-19. 